\title{
Contemporary Perspectives on Internationalization: Subnational, Regional, Digital
}

\author{
Maximilian Stallkamp \\ Ph.D. awarded by lvey Business School, Canada (October 2018)
}

\section{BIG Question:}

How is the internationalization of contemporary firms shaped by (1) subnational/regional factors and (2) by digital business models?

An important challenge for managers is how to expand a firm's reach into new markets. Recognizing this major challenge for practitioners, academic researchers have studied the phenomenon of firm internationalization for more than half a century. My dissertation makes the case that academic research on internationalization must evolve if it is to remain relevant and useful to practitioners. The internationalization patterns of firms have changed profoundly over the past half century and continue to evolve in response to technological progress (e.g., digitalization) as well as political and economic changes (e.g., regional economic integration, the resurgence of protectionism, the rise of emerging markets). To provide effective guidance to practitioners, research must address the realities of internationalization today. To this end, my dissertation aims to provide contemporary perspectives on internationalization, examining three different issues faced by today's internationalizing firms.

First, my dissertation addresses the subnational dimension of internationalization. Firms' international business strategies are often discussed at the country level, such as which country to invest in, or how to do business in country X. However, provinces, states, and cities within a single country can differ vastly in terms of economic development, infrastructure, and even culture. This means that managers have to decide not just which country to invest in, but also where within that country they should invest. Understanding subnational differences and choosing the right subnational location is especially important for firms operating in large, emerging markets, such as China, India, and Brazil, where differences between more developed and less developed areas are particularly stark. My research examines the subnational location choices of Japanese firms in China and shows that choosing certain types of subnational locations for their first investment in China can help firms expand more quickly afterwards.

Second, firms must increasingly consider supranational regional factors in addition to country-level and subnational factors. Regional economic integration (e.g., the European Union, ASEAN, NAFTA/USMCA) encourages firms to serve multiple countries in a region by adopting regional strategies. For many firms, this raises the question whether they should establish regional management centers in key regions to more effectively manage regional operations. This is the focus of the second part of my dissertation, which examines under which conditions firms introduce regional headquarters and so-called regional management mandates.

Third, many of today's fastest-growing and most innovative firms are so-called digital firms, whose products and services are purely digital. As digital products can be delivered virtually over the internet (for instance through websites and app stores), they can - in principle - be made available globally at very low cost. For this reason, it is often claimed that internationalization is comparatively easy for digital firms and can be 
achieved through purely virtual channels. However, my dissertation shows that this view is overly simplistic and may mislead practitioners. I found that digital firms continue to face significant barriers to internationalization and make use of a variety of different operating modes and internationalization strategies to serve foreign markets effectively.

\section{Part 1: Investing in China, but Where in China? The Importance of Sub- national Location Choice in Foreign Markets}

When a firm invests in a foreign country, does it matter where in the host country investment is located? Many countries are internally diverse, with substantial variation across cities and regions in terms of economic development, infrastructure, and market-supporting institutions. This challenge has been increasingly noted by practitioners (e.g., McKinsey, 2012). It is especially acute for firms operating in (or planning to enter) large emerging markets, where some areas have benefited from sustained economic development while others have been left behind.

Foreign firms investing in emerging markets tend to invest in relatively more developed subnational locations, especially for their first investment in a particular country. I examined over 10,000 foreign direct investments made by Japanese firms in China between 1993 and 2014, and I found that the vast majority was concentrated in major urban areas in a few coastal provinces. This intense clustering was remarkably stable over time, despite various government policies aimed at promoting investment in the country's interior, and despite rising costs in coastal provinces. Crucially, many Japanese firms invested in close proximity to other Japanese firms, leading to agglomerations of Japanese foreign subsidiaries.

I tested empirically whether there was any measurable benefit for Japanese firms entering China to locate their first investment in such a Japanese agglomeration. I found that these subnational locations with dense populations of other Japanese firms appear to aid new Japanese entrants in expanding more rapidly. Specifically, firms that entered in a subnational agglomeration were significantly faster to establish additional subsidiaries in other parts of China. This supports the view that the presence of "co-ethnic" Japanese networks within these agglomerations can provide new entrants with crucial resources and information that support further expansion in the host market. More generally, my findings suggest that managers should carefully consider where in a host country they invest, as the initial subnational location choice can have important long-term consequences. In doing so, they should consider not just "hard" factors such as physical infrastructure and econom- ic variables, but also the presence of home-country firms that might provide a useful social support network.

\section{Part 2: When Do Firms Establish Re= gional Headquarters or Other Re= gional Management Centers?}

Many multinational enterprises (MNEs) pursue regional strategies to capitalize on similarities between multiple countries in a region. For instance, many US-based multinationals have distinct regional strategies for Europe, Latin America, Southeast Asia, and other regions. Such regional strategies have become increasingly attractive with the formation of regional trade agreements and regional economic blocs (e.g., European Union, ASEAN, NAFTA/USMCA), which promote economic integration within regions. Regional strategies are sometimes-but not always_-supported by regional management structures, such as regional headquarters. The second part of my dissertation examines under which conditions firms introduce such regional management structures.

I developed and tested a theoretical model based on the following logic. As a firm expands its operations in a host region by establishing multiple foreign subsidiaries, the growing regional subsidiary network creates increasing demands for coordination and information processing on the parent firm. This can overwhelm the information processing capacity of the corporate headquarters, which is also geographically remote from the operations in the host region. To relieve the burden on corporate headquarters, MNEs establish regional management structures to create additional information processing capacity at the regional level. However, this does not necessarily mean that firms with many subsidiaries must establish a traditional regional headquarters (RHQ), i.e., a stand-alone organizational unit dedicated entirely to regional management functions. As RHQs are perceived as expensive and inflexible, many firms instead rely on regional management mandates (RMMs) assigned to an existing operating subsidiary in a region (Alfoldi, Clegg \& McGaughey, 2012).

I found that MNEs use RHQs and RMMs in different ways. Firms that have large numbers of subsidiaries in a region tend to choose RHQs, whereas a greater dispersion of subsidiaries across many countries in a region is associated with the allocation of RMMs to select operating subsidiaries. While I was not able to compare the relative effectiveness of RHQs and RMMs, my research does suggest that practicing managers differentiate between the two and that a distinct 'use case' exists for both RHQs and RMMs. 


\section{Part 3: How Can Digital Firms Serve Foreign Markets Effectively?}

Digitalization - the increasingly pervasive use of advanced digital technologies in business and society-has the potential to transform how firms internationalize. This is particularly the case for so-called digital firms, which produce purely digital products and services. Examples include business services (e.g., Shopify, Twilio), social media (e.g., Facebook, Snap), games and entertainment (e.g., Epic Games, Netflix), or marketplace-like platforms that facilitate trade in physical goods and offline services (e.g., Uber, Airbnb, Etsy).

Since digital products and services can be delivered virtually over the internet to users almost anywhere in the world, it is often assumed that internationalization is comparatively easy for digital firms. Digital firms, according to this line of thinking, can simply make their digital products available globally over the internet, without having to establish factories, supply chains, or other physical facilities abroad (e.g., UNCTAD, 2017). By extension, digital firms are often assumed to be 'born global', meaning that they serve worldwide markets from inception (e.g., McKinsey Global Institute, 2016).

The third part of my dissertation questions this common narrative of inherently global digital firms that easily serve worldwide audiences through online channels. I studied 17 different digital firms from 3 continents (North America, Europe, and Asia), operating in different industries. Based on interviews with key decisionmakers (founders, CEOs, senior managers) and additional secondary materials, I analyzed (1) the foreign operation modes of digital firms, and (2) the temporal and geographic patterns of their internationalization.

I found that, rather than relying entirely on virtual internet-based exports, digital firms use a variety of different modes to serve foreign markets. From a technical perspective, digital products and services can easily be exported through purely virtual channels, such as app stores and websites. However, most firms in my sample found that they still required some sort of physical presence in foreign markets. This is often necessary to provide sales, marketing and customer service functions, to build relationships with stakeholders, and to resolve unexpected problems on the ground. Moreover, having 'boots on the ground' (as one executive put it) was in many cases seen as critical for understanding foreign markets and adapting products to local needs. Not all digital firms need to establish conventional foreign subsidiaries in each foreign market. Instead, the firms I studied used a mixture of foreign subsidiaries, regional offices, and flexible arrangements based on temporary executive postings and external partners.

Similarly, digital firms are not necessarily 'born global'. Some of the sample firms did in fact make their product available globally and gained international users from the outset. However, most pursued more deliberate market entry strategies, releasing their products or services in select markets only. Interestingly, firms' early international expansion efforts often targeted proximate countries in their home region, mirroring well-established internationalization patterns observed among conventional firms, albeit at an accelerated pace. I identified several constraints that limit the ability of many digital firms to serve global markets from the start. Among them are the need for local adaptation (e.g., to meet local tastes, preferences, or regulatory requirements) and the need for local-language sales and customer support services. Many digital firms also operate platform business models that require a critical mass of local complementors (e.g., restaurants, drivers, developers) in each foreign market (Stallkamp \& Schotter, 2019). These constraints force many digital firms to adopt a more deliberate, country-by-country internationalization strategy.

The high-level conclusion is that digitalization does not eliminate the challenges of internationalization, even for firms with purely digital products. Although digital technologies create new ways of engaging with foreign markets, many digital firms still require 'boots on the ground' and face limitations in how quickly they can scale internationally. A better understanding of how digital firms internationalize is crucial for entrepreneurs, executives, and investors in digital firms, as well as for the academics studying them.

\section{Implications and Conclusion}

Beyond the implications for academic research discussed in the dissertation, there are several implications for practitioners (managers, entrepreneurs, investors, government officials). In terms of location choice, my findings indicate that a firm's initial subnational location choice in a host country can have important long-term consequences for the firm's subsequent expansion in the country. This suggests that executives need to analyze foreign investment location choices at a fine-grained subnational level and take into account potential benefits from locating close to foreign direct investments made by firms from the same home country. Policy makers and government officials seeking to attract foreign investment may want to leverage existing foreign investment from a particular country to attract further investment from that country. My findings on regional management structures suggest that firms with a growing foreign subsidiary footprint in a specific region should consider different forms of regional management centers. While RHQs and RMMs are to some extent substitutable, RMMs appear to be more suitable for some conditions and RHQs for others. Finally, my research on digital firms shows that the internationalization of these firms is more complex than commonly acknowledged. Rather than assuming that any digital firm can scale globally using only virtual channels, a more realistic un- 
derstanding of each individual digital firm's business model is needed. In many cases, some form of physical presence is still required and selective, country-by-country internationalization strategies are necessary.

This dissertation provides new insights on how firms internationalize in the 21st century. Contemporary internationalization is about more than just country-level market entry decisions, the establishment of overseas manufacturing plants, and cross-border flows of physical goods. Firms operate in a complex, multi-layered environment that presents challenges and opportunities at the subnational, country, and regional level, and increasingly also in the digital sphere. The internationalization of firms remains an important and challenging issue for researchers and practitioners alike. ${ }^{1}$

\section{References}

Alfoldi, E. A., Clegg, L. J., \& McGaughey, S. L. 2012. Coordination at the edge of the empire: The delegation of headquarters functions through regional management mandates. Journal of International Management, 18(3): 276-292.

McKinsey Global Institute. 2016. Digital globalization: The new era of global flows. http://www.mckinsey.com/business-functions/ digital-mckinsey/our-insights/digital-globalization-the-new-era-ofglobal-flows.

McKinsey \& Co. 2012. Winning the $\$ 30$ trillion decathlon. Going for gold in emerging markets. https://www.mckinsey.com/business-functions/strategy-and-corporate-finance/our-insights/winning-the-30-trillion-decathlon-going-for-gold-in-emerging-markets

Schotter, A., Stallkamp, M., \& Pinkham, B. 2017. MNE headquarters disaggregation: The formation antecedents of regional management centers. Journal of Management Studies, 54(8): $1144-1169$.

Stallkamp, M., \& Schotter, A. P. 2019. Platforms without borders? The international strategies of digital platform firms. Global Strategy Journal. Advance online publication. https://doi.org/10.1002/ gsj. 1336

Stallkamp, M., Pinkham, B., Schotter, A. \& Buchel, O. 2018. Core or periphery? The effects of country-of-origin agglomerations on the within-country expansion of MNEs. Journal of International Business Studies, 49(8): 942-966.

UNCTAD. 2017. World investment report 2017: Investment and the digital economy. http://unctad.org/en/pages/PublicationWebflyer. aspx? publicationid $=1782$

\section{Endnotes}

1 Note: Versions of Essay 1 and Essay 2 have been published as co-authored articles (Stallkamp, Pinkham, Schotter \& Buchel, 2018; Schotter, Stallkamp \& Pinkham, 2017).
Maximilian Stallkamp (mstallkamp@vt.edu) is an Assistant Professor at Virginia Tech. His research and teaching interests are in international strategy, with a special focus on firms with digital and platform-based business models. Max's research has been published in the Journal of International Business Studies, the Journal of Management Studies, and the Global Strategy Journal. 